\title{
Fifth Seminar on the Middle East
}

Studies of the Middle East and the Islamic world have developed considerably in Argentina over the last 10 years because, among other reasons, this country was targeted twice by terrorists who still remain unknown: The Embassy of Israel was bombed in 1992, and the central headquarters of the Jewish community (AMIA) was bombed in 1994. Given that even today we do not know who carried out these attacks and why, the topic of the Middle East has acquired a public dimension that it did not have before. In fact, these actions led to the creation of university study centers and chairs dedicated to the study of the Arab and Islamic worlds. ${ }^{1}$ However, their academic output is still in the initial stage.

On 10-11 November 2004, the Fifth Seminar on the Middle East conference took place at the Universidad Nacional de La Plata (UNLP), in La Plata, Argentina. The Department of the Middle East of the UNLP's Institute of International Relations organizes this conference every 2 years, since it is one of the few universities that has a specific department dedicated to Middle Eastern studies. Moreover, it is the only one that has, since 1997, consistently managed to bring Argentine academics together to share ideas and discuss the contemporary reality of the Middle East and the Islamic world.

During this conference, articles were presented on a wide range of themes, always searching for the best way to link together the most relevant events of contemporary reality. For this reason, in 2002 the focus was on the implications of the 9/11 tragedy. The current conference concentrated on the war in Iraq, a logical continuation of the discussion in 2002.

Professors from 14 Argentine universities, as well as from Spain, the United States, and Mexico, participated in the panels. The first panel analyzed Islamic thinking and practice after 9/11. Augustín Galli (University of Buenos Aires [UBA], Argentina) laid out the evolution of Islamic movements in Algeria. Damián Setton (UBA), who is investigating the various 
religious communities in the cities of Iguazú, Foz De Iguazú, and Ciudad del East (where the borders of Argentina, Brazil, and Paraguay meet in the “Triple Border”), explained that all accusations that these locales are centers of Islamic terrorist activity are false claims based more on political considerations than on reality.

Enrique Herszkowich (UBA) focused on the debates that have taken place, ranging from the collision of civilizations and multiculturalism to the universal understanding of human rights. Pedro Brieger (UBA/UNLP) explained the development of al-Qaeda as a nontraditional Islamic movement that has clearly differentiated itself from those Islamic movements that, as political formations, seek political power through mass popular support within the borders of one country.

Two panels discussed American-Iraqi relations and the process of Iraq's post-war reconstruction, a topic that has raised quite a few debates about the American intervention and the real chance of establishing democracy there. As was also the case in the 2002 conference, the participants adopted a critical tone toward American political unilateralism in the Middle East, the doctrine of preventive war, and the ensuing demonization of Islam.

James Quirk (Loyola College in Maryland, USA) raised the point that coercive democratization by means of foreign occupation has not been a novel idea since the days of post-World War II Germany and Japan. Professor Dergghoukassian (Universidad de San Andrés, Argentina) argued that the Greater Middle East project is, in essence, neo-Wilsonian and needs to include an economic and military compromise on the part of the United States. However, given the international situation, it will fail. These statements were criticized by several presenters, who questioned the doctrine of preventive war and the unipolar design of the premier global power, because, as Renée Isabel Mengo (Universidad de Córdoba, Argentina) pointed out, unilateralism and military power cannot reproduce their models of society and culture. According to Patricia Kreibohm (Universidad de Tucumán, Argentina), since 1941 the United States has undertaken three grand global crusades (viz., against Nazism, communism, and terrorism), the last one of which has the least amount of legitimacy and has provoked questioning about its global leadership.

Juan Aníbal Gonzalez pointed out that the geostrategic objective of invading Iraq was part of a global project designed to assert control over the region's petroleum resources. Susana Adamo and Miriam Jaime (both of Universidad de Salta, Argentina) insisted that the United States has started an era of permanent war and "infinite justice" by ignoring international conven- 
tions and laws. Zidane Zeraoui (Instituto Tecnológico de Monterrey, Mexico) presented an article on the Kurdish problem, in which he asserted that the next Iraqi regime will also have authoritarian characteristics and will disregard the Kurds' aspirations for a federal - or even an independent - state.

One of the most outstanding panels was the one on the PalestinianIsraeli conflict and the new international reality produced by the American invasion of Iraq. According to Emanuel Pfoh (UNLP), reinterpreting the history of both peoples is key to establishing their legitimate claims to the disputed territories. Nevertheless, Julia Hoppstock (Universidad de San Andrés) stated that the negotiations depend upon the existence of a "mutually hurting stalemate" that strengthens the leaders' acceptability. Valeria Frediani (UNLP) analyzed the conflict from the perspectives of the wall being built by Israel, a legal opinion based upon international law, and the intervention of the International Court of Justice.

The final panel consisted of two reports that analyzed Iran and Shi ism as being at the root of the American invasion of Iraq. Luciano Zaccara (Universidad Autónoma de Madrid, Spain) suggested that the government in Tehran has benefited the most from the wars in Afghanistan and Iraq by its neutral posture and collaboration with the United Nations. He discussed the paradox that the declared enemy of the Islamic revolution has eliminated two political regimes that, at that time, were also at odds with Iran. Pable Wehbe (Universidad Nacional de Río Cuarto, Argentina) analyzed the American invasion of Iraq in light of the expectations of the Shi ah majority to shape a government based upon the western idea of "one man - one vote" and the illusion of devising a political system similar to that of Iran.

In the concluding session, the participants agreed on the necessity of maintaining, on a regular basis, these sessions organized by the Institute of International Relations' Department of the Middle East, as well as the importance of increasing communication with academics in other countries, especially with those in the Arab and Islamic worlds.

\section{Endnote}

1. See Pedro Brieger and Enrique Herszkowich, "The Muslim Community in Argentina,” The Muslim World 92, nos. 1 and 2 (spring 2002): 157-68.

Pedro Brieger

Chairperson, Department of the Middle East Institute of International Relations, Universidad de La Plata, La Plata, Argentina (trans. by Jay Willoughby [AJISS] and Roberto Marín-Guzmán [University of Costa Rica]) 